\title{
INFLUENCE OF ORTHODONTIC MINI-SCREW SURFACE MODIFICATIONS ON IMPLANT TOPOGRAPHY AND OSSEOINTEGRATION: AN IN- VIVO STUDY
}

\author{
Rehab Rizk El-Zehary *, Marwa A. Tawfik ${ }^{* *}$, Samah I. Mourad ${ }^{* * *}$ and Enas T. Enan ${ }^{* * * *}$
}

\begin{abstract}
Introduction: Implant-supported orthodontic treatment has gained an expanded interest by researchers and orthodontists in the recent years. Therefore, different methods were tried to achieve the best results in this kind of treatment.

Aim of the study: The current research was conducted to compare the effect of 2 different treatment methods on the surface of orthodontic titanium mini-screws and on bone response to the treated implants.

Materials and methods: Forty-eight titanium mini-screw implants were distributed under 3 equal groups; as received, sandblasted, and laser-treated, respectively. After application of the surface-treatment methods, half of the selected screws were tested for surface morphology, using a scanning electron microscope (SEM) and a digital profilometer. To evaluate the biological effects of surface treatment methods, the other screws were implanted in rabbits' tibias which were subjected to histological examination at the end of the experimental periods of 4 and 8 weeks. The surgical procedures and euthanasia were conducted according to the limitations of Research Committee of Mansoura University.
\end{abstract}

Results: Sandblasted implants showed the highest surface roughness and the most pronounced bone response.

Conclusion: Sandblasting surface treatment provide more favorable conditions for implant osseointegration, in comparison to laser-treatment.

KEYWORDS: Laser-treatment, Orthodontic mini-screw, Surface-treatment, Sandblasting.

\footnotetext{
* Associate Professor, Oral Biology Department, Faculty of Dentistry, Mansoura University, Egypt. ** Associate Professor, Orthodontic Department, Faculty of Dentistry, Mansoura University, Egypt.

***Associate Professor, Oral and Maxillofacial Surgery Department, Faculty of Dentistry, Mansoura University, Egypt. ****Associate Professor, Dental Biomaterials Department, Faculty of Dentistry, Mansoura University, Egypt.
} 


\section{INTRODUCTION}

Titanium mini-implants have been widely employed for tooth replacement, support of transitional prosthesis, stabilization of complete denture, and for orthodontic anchorage. Mini-implants provide a simpler method of placement and removal, and less traumatic procedures than other forms of dental implants. ${ }^{1-4}$. For orthodontic purposes, mini-implants (mini-screws) can often be immediately loaded, leading to reduced postoperative patient morbidity, and minimizing bone resorption during healing ${ }^{2,5}$.

Osseointegration, which was first introduced by Brånemark et al. (1960), stands for direct structural and functional contact between the implant surfaces and the surrounding bone without soft tissue in between $^{6}$. Osseointegration is crucial for stable fixation of titanium to bone and it also raises the success rates of mini dental implants as temporary anchorage devices ${ }^{6,7}$. To produce the reduced-size mini-screws with high fracture strength, titanium alloy $\left(\mathrm{Ti}_{6} \mathrm{Al}_{4} \mathrm{~V}\right)$-rather than commercially-pure titanium (cpTi)- is used. However, this alloy is characterized by lower osseointegration potential and higher corrosion susceptibility in-vivo, which can reduce the implant stability and its long-term success ${ }^{5,8}$. According to Albrektsson et al. ${ }^{9}$, surface topography and chemistry of dental implants, have an essential impact on their osseointegration. It was shown by previous studies ${ }^{10-12}$ that surface treatment methods of implants have positive effects on the bone to implant bond. Plasma spraying, acid etching, hydroxyapatite coating, sandblasting, and laser-treatment are some of most commonly used methods for treatment of implant surfaces ${ }^{5,13,14}$.

Sandblasting is one of the approaches used to directly enhance the osseointegration and increase the biological properties of orthodontic mini implants. It is applied by removing portions of the external layer of the implant, using abrasive aluminum particles within a grit blasting environment ${ }^{15}$. Sandblasted titanium implant exhibits improved bone contact and better removal torque ${ }^{\mathbf{1 6}}$. Nevertheless, the mechanism of improved bone response to this kind of treatment has not yet been totally assessed ${ }^{17}$.

Laser treatment of a titanium implant is a highly reliable choice to roughen its surface without using particles or chemicals. It is applied in different techniques due to its efficiency in creating micro- and nano-scale surface roughness rapidly. Moreover, laser induces surfaces of complex features and higher purity in comparison to other surface treatment methods ${ }^{18,19}$. It is viewed as a promising method for surface modification of dental implants, where it enhances the surface properties for osseointegration, resulting in a better and faster implant-bone retention in comparison to other treatment methods ${ }^{\mathbf{2 0}}$.

Types and applications of laser differ according to the wavelength, frequency, divergence and direction of the laser beam ${ }^{21}$. $\mathrm{Co}_{2}$ laser (wavelength of $10600 \mathrm{~nm}$ ) is not absorbable by metallic surfaces, so it can be applied for uncovering implants ${ }^{22}$. In contrast, the Nd-YAG (neodymium-doped yttrium aluminum garnet; $\mathrm{Nd}: \mathrm{Y}_{3} \mathrm{Al}_{5} \mathrm{O}_{12}$ ) laser (wavelength $1064 \mathrm{~nm}$ ) is highly absorbed by metallic surfaces, so it is the most commonly applied for surface treatment of titanium implants ${ }^{\mathbf{2 0}, 23-25}$. It was proved that Nd-YAG laser irradiation can lead to either melting or other surface alteration. Thus, the use of this laser type is contraindicated for sterilization or decontamination of implants before their placement ${ }^{22}$.

Although laser treatment has a vital impact on cell reaction to dental implants; further studies are required, using different types of laser, in order to evaluate the influence of these modifications on osseointegration ${ }^{26}$. Moreover, there is a growing need for further protocols with a newly surface modification to improve the dental mini-implant microstructure and altering their surface properties. Thus, the current study was undertaken to investigate the influence of different surface treatment methods on bone response to orthodontic titanium mini-screws. 


\section{AIM OF THE STUDY}

The present study aimed to investigate the effect of 2 different types of surface modifications on bone response to the treated titanium mini-screws. Sandblasting and Nd-YAG laser treatment techniques were applied to titanium mini-implants and their effect on surface topography and osseointegration were evaluated in comparison to the untreated implant machined surfaces.

\section{MATERIALS AND METHODS}

\section{Implant surface modification treatments:}

A total of 48 titanium alloy mini-screws of $1.8 \mathrm{~mm}$ diameter and $8 \mathrm{~mm}$ length (3M Unitek Orthodontic Products; Monrovia, California, United States) were used in this study. Half of this number was used for the surface topographic measurements, while the other half was applied for the in-vivo implantation and histological examination. The selected screws were classified into 3 groups, according to the type of applied surface treatment; machined, sandblasted and laser treated.

In group I (control), the implants were left untreated (as machined by the manufacturer). For group II, the implants were removed from their sterile package to the sand-blasting process ${ }^{27}$. The sand-blaster machine (AX-B3 sandblaster unit, Tianjin, China) contained aluminum oxide $\left(\mathrm{Al}_{2} \mathrm{O}_{3}\right)$ particles of $110 \mu \mathrm{m}$ size, which were sprayed on the implant surface at a pressure of 4 bar for 2 minutes. During sandblasting, the blast nozzle was held $2 \mathrm{~cm}$ away from the implant, at a perpendicular orientation to its surface ${ }^{28-30}$. In group III, the mini-implants were subjected to pulsed Nd:YAG laser (1064 nm wavelength). The treatment was performed at a frequency of $20-35 \mathrm{kHz}(\mathrm{v})$, pulsing intervals of $300 \mathrm{~ns}$, energy of $90-100 \mathrm{~mJ} /$ pulse, scanning speed between 80 and $300 \mathrm{~mm} / \mathrm{s}$, scanning space of 0.1 $0.2 \mathrm{~mm} / \mathrm{s}^{20}$. During laser treatment, the screw was fixed in a baker containing an alginate mix which was chosen due to its inertness and easy removal.
After implants' treatment, they were cleaned using a digital ultrasonic cleaner (MCS, P4820, China), then each implant was packed in a sealed sterilization pouch and sterilized in a steam autoclave to be ready for implantation ${ }^{29,30}$.

\section{Surface characterization}

To compare surface morphology of the tested groups, a total of 24 titanium mini-screws used. After sandblasting and laser treatment, 3 specimens from each group were scanned under a scanning electron microscope (SEM) (JEOL, T-20; Japan) at a magnification of $\times 2000{ }^{31}$. To measure surface roughness, 5 specimens from each group were tested with a digital profilometer (Surf Test SJ 210 Analyzer; Mitutoyo Corp, Japan) at a measuring force of $0.75 \mathrm{mN}$ and a tip radius of $2 \mu \mathrm{m}$. For this purpose, the roughness average $(\mathrm{Ra})$ parameter was measured for each specimen, where the moving speed of the diamond stylus was set at $0.5 \mathrm{~mm} / \mathrm{s}$ for a tracing length of $2 \mathrm{~mm}$. For each screw, the same procedure was performed 3 times to calculate its average Ra value. To avoid serrations of the screw, Ra measurements were made at the flat head of the screw, which received a similar treatment to that of the screw root.

\section{Animals}

Twenty- four adult white clinically healthy rabbits 9-12 months old (each weighing 3.1 to $4.0 \mathrm{~kg}$ ) were used in this section of the study. The selected animals were kept in individual cages and had access to water and balanced diet and libitum. Regular cleaning and ventilation of the housing room were assured. The Experimental protocol was conducted after approval of the Dental Research Ethics Committee of the faculty of Dentistry, Mansoura University (protocol code no.: 13010119).

\section{Experimental Design}

The twenty four adult rabbits were divided into 8 rabbits for each group. In group I (control), the 
implants were left untreated (as machined by the manufacturer). For group II, the implants were subjected to sandblasting. In group III, the miniimplants were subjected to pulsed Nd:YAG laser (1064 nm wavelength).

\section{Surgical procedures}

All rabbits were subjected to identical surgical procedures under general anesthesia. General anesthesia was achieved with intramuscular injection with zolazepam $15 \mathrm{mg} / \mathrm{kg}$ (Zoletil 50; Virbac, Madrid, Spain) and xylazine $5 \mathrm{mg} / \mathrm{kg}$ (Rompun; Bayer, Leverkusen, Germany). A pre-operative dose of antibiotic (Amoxicillin; Pfizer, Barcelona, Spain) was injected intramuscularly. Then the animal were given a subcutaneous injection of $1 \mathrm{ml}$ of local anaesthetic (3\% Prilocaine-felypressin, Astra, Mexico) at the site of surgical operation to enhance analgesia and decrease bleeding.

After hair shaving and skin exposure, the area over the tibia was disinfected using a sterile cotton pellet wet with sterile povidine iodine $7.5 \%$ (Betadine, Codipha, Mundipharma, Cyprus) ${ }^{17}$. The implant site was reached through a $4 \mathrm{~cm}$ long incision of the skin and underlying fascia, and the tibia was exposed using a Molt elevator. The sharp tip, selfdrilling and self-tapping mini-screw was removed from its sterile package without any contamination and then, under copious saline irrigation, it was installed in the tibia using the supplied manual screwdriver at a constant rotational drilling with a uniform torque according to the manufacturer's instructions (Fig.1). The implants were drilled to penetrate only the first layer of cortical bone. The incision was then sutured, where 5-0 resorbable vicryl sutures (polyglactin 910; Ethicon) were used for fascia and periosteum, and 4/0 black silk sutures were used for the skin. A single postoperative dose of $600,000 \mathrm{IU}$ Benzetacil was administrated ${ }^{\mathbf{1 7}}$. After surgical implantation, the animals were kept in a cage under supervision of the responsible veterinary doctor until they relieved from general anesthesia. During the healing period (4 and 8 weeks), the animals were carefully monitored for wound healing progress around and over the installed mini-implants, and the wound was protected from infection using a povidone iodine ointment. At the end of each experiment period (4 weeks and 8 weeks), four animals from each group were subjected to euthanasia using an overdose of ketamine $(2 \mathrm{ml})$ and xylazine $(1 \mathrm{ml})$ intravenous injection. The 8 weeks period was applied because it represents one cycle of bone turnover in rabbits ${ }^{31,32}$.

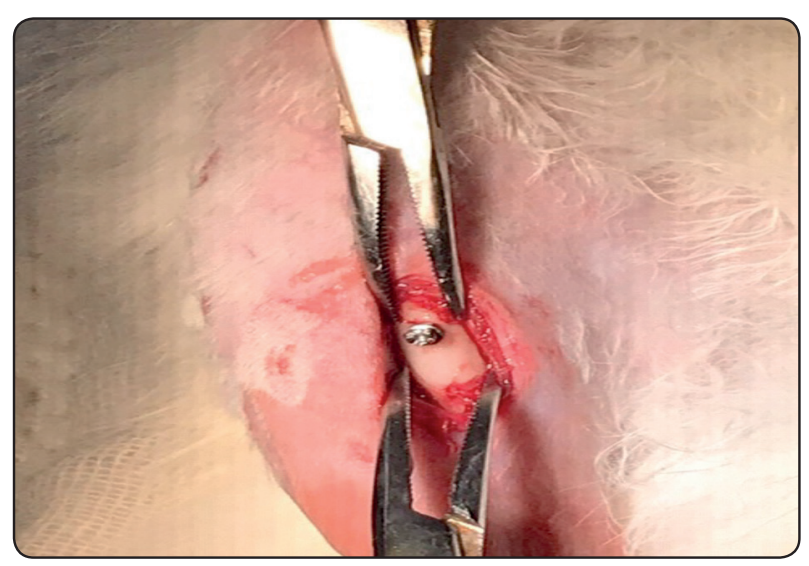

Fig. (1) Photograph showing mini-implant installed into the prepared bed in the right rabbit tibia.

\section{Histological, histochemical and histomorpho- metric Examinations}

At necropsy, sharp dissection was applied to retrieve the right tibias after removal of the soft tissue using surgical blades. The specimens at predetermined site were dissected and placed in $10 \%$ formalin solution for $48 \mathrm{~h}$. Then the specimens were subjected to decalcification for 6 weeks, using a solution of $50 \%$ formic acid and $20 \%$ sodium citrate. After 18 days of decalcification, screws were removed carefully from the subperiosteal bone. Following fixation and decalcification, the bone was embedded in Paraffin. Serial thin sections $(5-\mu \mathrm{m})$ were cut along the center of the circular defects. Hematoxylin \& eosin (H\&E) and alkaline phosphatase stains were used to stain sections from 
each block, and histomorphometric analysis was made for the central sections.

\section{Computer Assisted image analysis}

Images of hard tissue around the screws were captured, digitized and saved as TIFF. The analysis was performed using VideoTest Morphology® software (Russia), with a specific built-in routine for area calculation for histological and histomorphometrical assessments of healing process. Six slides from each specimen were prepared and 6 random fields were analyzed from each slide. The routine includes exclusion of empty areas and calculation of $\%$ area of bone porosity around implant in relation to total bone area and mean pixel intensity of alkaline phosphatase stain were calculated and averaged. All results were exported to . XLS file and used in statistical analysis.

\section{STATISTICAL ANALYSIS:}

The collected data were tabulated and analysed using Statistical package for Social Science (SPSS) (SPSS Statistics for Windows, Version 25.0. Armonk, NY: IBM Corp.). Student T-test was applied to evaluate the significance of difference between two group's means. For the comparison of more than two groups' means, one-way analysis of variance (ANOVA) was used, with post hoc test. Paired sample T test was applied to evaluate changes in parameters with time. The reported $p$ values were two-tailed and $\mathrm{p}<0.05$ was considered to be significant.

\section{RESULTS}

\section{Surface roughness and topography:}

Table 1 shows means and standard deviations for surface roughness $(\mathrm{Ra})$ test of all groups under investigation. The highest $\mathrm{Ra}$ mean value was recorded for group 2 of the sandblasted miniimplant $(0.551 \mu \mathrm{m})$, while group I of the control implant showed the lowest value $(0.294 \mu \mathrm{m})$. One- way ANOVA test indicated a significant difference among the tested groups $(\mathrm{p}<.0001)$.

TABLE (1) Ra results for all groups $(\mu \mathrm{m})$.

\begin{tabular}{|l|c|c|c|c|c|}
\hline & Mean & SD & F-value & P-value & LSD \\
\cline { 1 - 3 } Control & $0.294^{\text {С }}$ & 0.044 & 57.02 & $<.0001$ & 0.052 \\
\cline { 1 - 3 } Sand-blasted & $0.551^{\mathrm{A}}$ & 0.044 & & & \\
\cline { 1 - 3 } Laser-treated & $0.440^{\text {в }}$ & 0.038 & & & \\
\hline
\end{tabular}

Means with the same superscript letter are not significantly

different at $P \leq 0.05$

Least significant difference (LSD) test revealed significant differences between group I (control) and each of groups II and III. Significant differences were also found between group II (sand-blasted) and group III (laser-treated).

Scanning electron micrographs of the studied implants are shown in (Fig. 2). As could be noted in (Fig. 2A) of the control specimen, except for the machining marks, the surface of titanium mini-implant was smooth and regular. The SEM examination of sand-blasted implants in (Fig. 2B), showed severe roughness of the implant surface. Due to the impact of sandblast particles, pits and grooves were generated on the implant, causing the primary surface roughness. Furthermore, secondary roughness was generated by the sandblast particles that remained attached to the implant surface. While (Fig. 2C) of the laser-irradiated specimen displayed extensive partial melting and crater formation. Because of the extensive melting caused by laser, a relatively smooth surface was found.

\section{Clinical findings}

Wound healing in all the experimental rabbits was progressing normally with no signs of persisting inflammation or infection at the surgical site except for one rabbit which was treated by application of fucidic acid antibiotic 15g cream 2\% (Fucidin, 

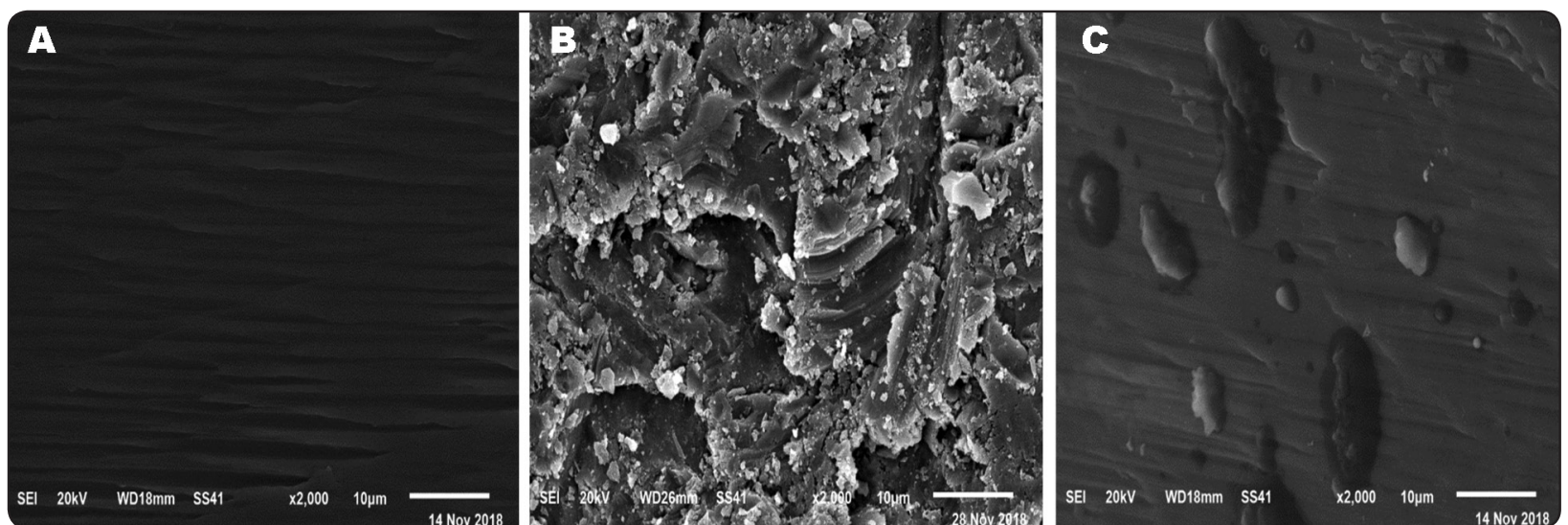

Fig. (2). Scanning electron micrographs (×2000 magnification) showing surfaces of: A, Control un-treated implant. B, Sandblasted implant. C, Laser-treated implant.

PH.EUR.20mg/g in a cream base). Postoperatively, no signs of infection in or around the implant site could be detected. Moreover, no evidence of wound dehiscence, or rejection.

\section{Histological, histomorphometric and statistical evaluations}

Histological sections of bone - implant interface for group I at 4 weeks showed newly formed bone trabeculea containing healthy osteocytes and rimmed with osteoblasts with granulation tissues zone that was detected at the interface area indicating the bone healing process (Fig. 3A, A1). Group II showed increased thickness of more organized newly-formed bone trabeculea (Fig. 3B, B1). In Group III, the bone cavities showed numerous newly formed bone trabeculea separating wide marrow spaces with less organized pattern as shown in (Fig. 3C, C1). As shown in table (2) and (Fig. 6), regarding \% of bone porosity, there was significant difference between all studied groups after 4 weeks $(\mathrm{p} 1<0.001)$, this difference was attributed to significantly lower mean in group II as well as in group III when compared to control group (p2,3<0.001 for each). In addition, group II showed significantly lower mean when compared to group III (p4<0.001).

At 8 weeks, histological sections of bone - im- plant interface for all groups showed that bone cavities had more revealed organized bone trabeculae with osteon and haversian system. Group II showed a definite line demarcating the old bone from the newly formed bone. Lamellar bone was apparently formed in group II and group III than group I. The osseointegration was improved within group II and III but more apparently in group II (Fig. 4 A, A1, B, B1, C, C1). Group I had the least implant-bone integration and calcified bone, while the II group had a marked increase of implant-bone integration and calcified bone. Moreover, there was significant difference between all studied groups after 8 weeks $(\mathrm{p} 1<0.001)$, this difference was attributed to significantly lower mean in group II as well as in group III when compared to control groups ( $22,3<0.001$ for each). In addition, group II showed significantly lower mean when compared to group III $(\mathrm{p} 4<0.001)$ as shown in table (2) and (Fig. 6).

Regarding alkaline Phosphatase enzyme reaction, the specimens from group I after 4 weeks revealed mild alkaline phosphatase enzyme reaction especially on the peripheries. In group II; the newly formed bone trabeculae showed an intense reaction to alkaline phosphatase enzyme. In group III; the bone trabeculae showed moderate reaction to alkaline phosphatase enzyme. (Fig. 5 A, B, C). After 8 weeks; group I showed mild reaction to alkaline 
TABLE (2) Comparison of the Area fraction of bone porosity and intensity of alkaline phosphatase stain between all studied groups across follow up points.

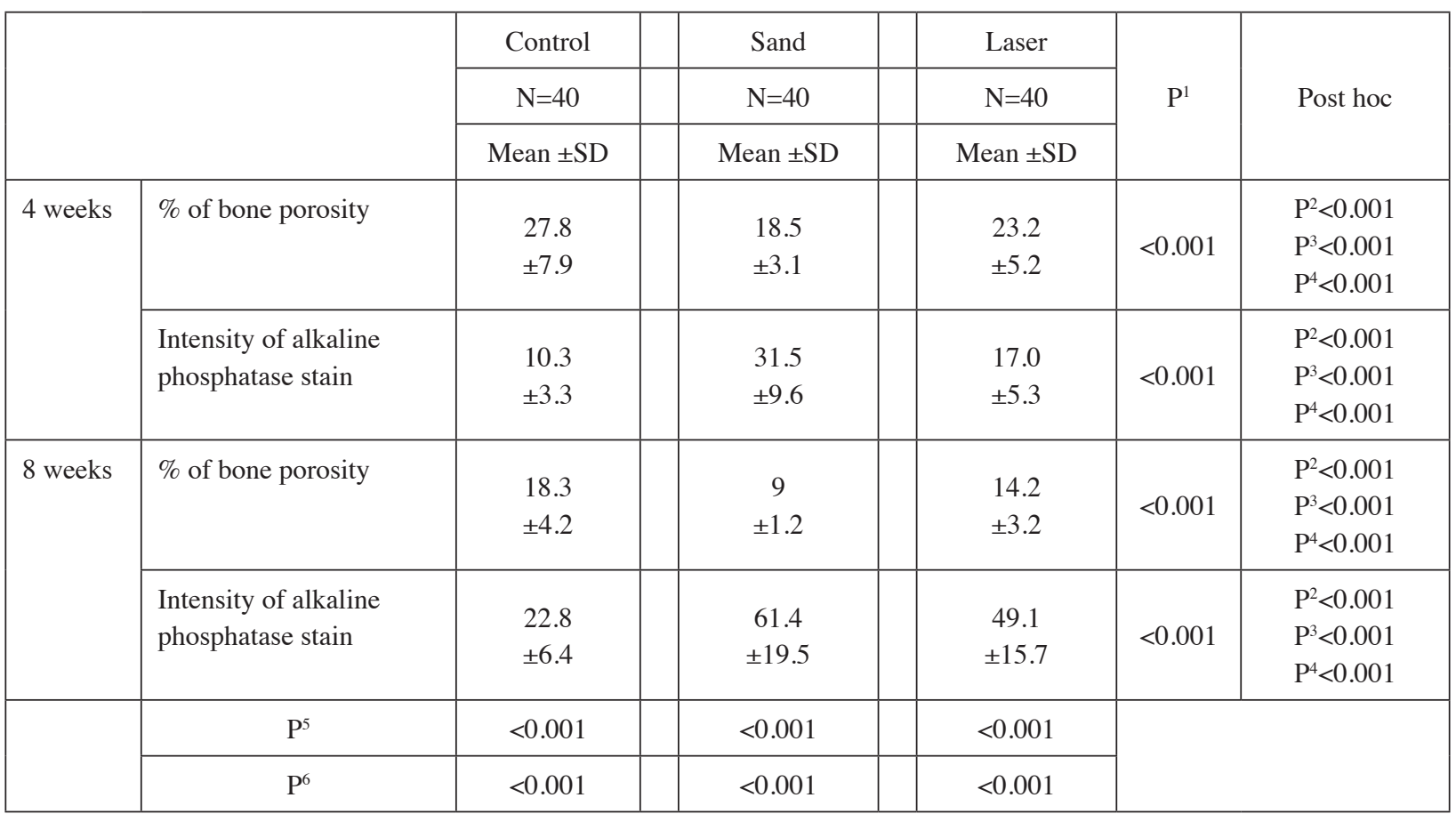

P1, comparison between all studied groups using ANOVA; p2, comparison between control and laser groups; p3, comparison between control and sand groups; 4 , comparison between sand and laser groups; p5, comparison between 1st and 2nd month measures regarding \% of bone porosity in each group using paired sample t test. P6, comparison between 1st and 2 nd month measures regarding Intensity of alkaline phosphatase stain in each group using paired sample t test.

phosphatase enzyme. In group II; the bone- implant interface had a network of trabeculae with highly intense reaction to alkaline phosphatase enzyme. In group III; new bone trabeculae showed moderate to intense reaction to alkaline phosphatase enzyme. (Fig. 5 A1, B1, C1).

As shown in table (2) and (Fig. 7), regarding intensity of alkaline phosphatase stain, there was significant difference between all studied groups after 4 weeks $(\mathrm{p} 1<0.001)$, this difference was attributed to significantly higher mean of intensity of alkaline phosphatase stain in group II as well as in group III when compared to control group ( $22,3<0.001$ for each). In addition, group II showed significantly higher mean of intensity of alkaline phosphatase stain when compared to group III (p4<0.001).

In addition, there was significant difference between all studied groups after 8 weeks $(\mathrm{p} 1<0.001)$, this difference was attributed to significantly higher mean of intensity of alkaline phosphatase stain in group II as well as in group III when compared to control group (p2,3<0.001 for each). Moreover, group II showed significantly higher mean of intensity of alkaline phosphatase stain when compared to group III ( $\mathrm{p} 4<0.001)$.

Comparing between 4 and 8 weeks revealed that significant decrease in mean $\%$ of bone porosity as well as significant increase in intensity of alkaline phosphatase stain after 8 weeks when compared to 4 weeks in each group (p5, p6 $<0.001$ for each). 


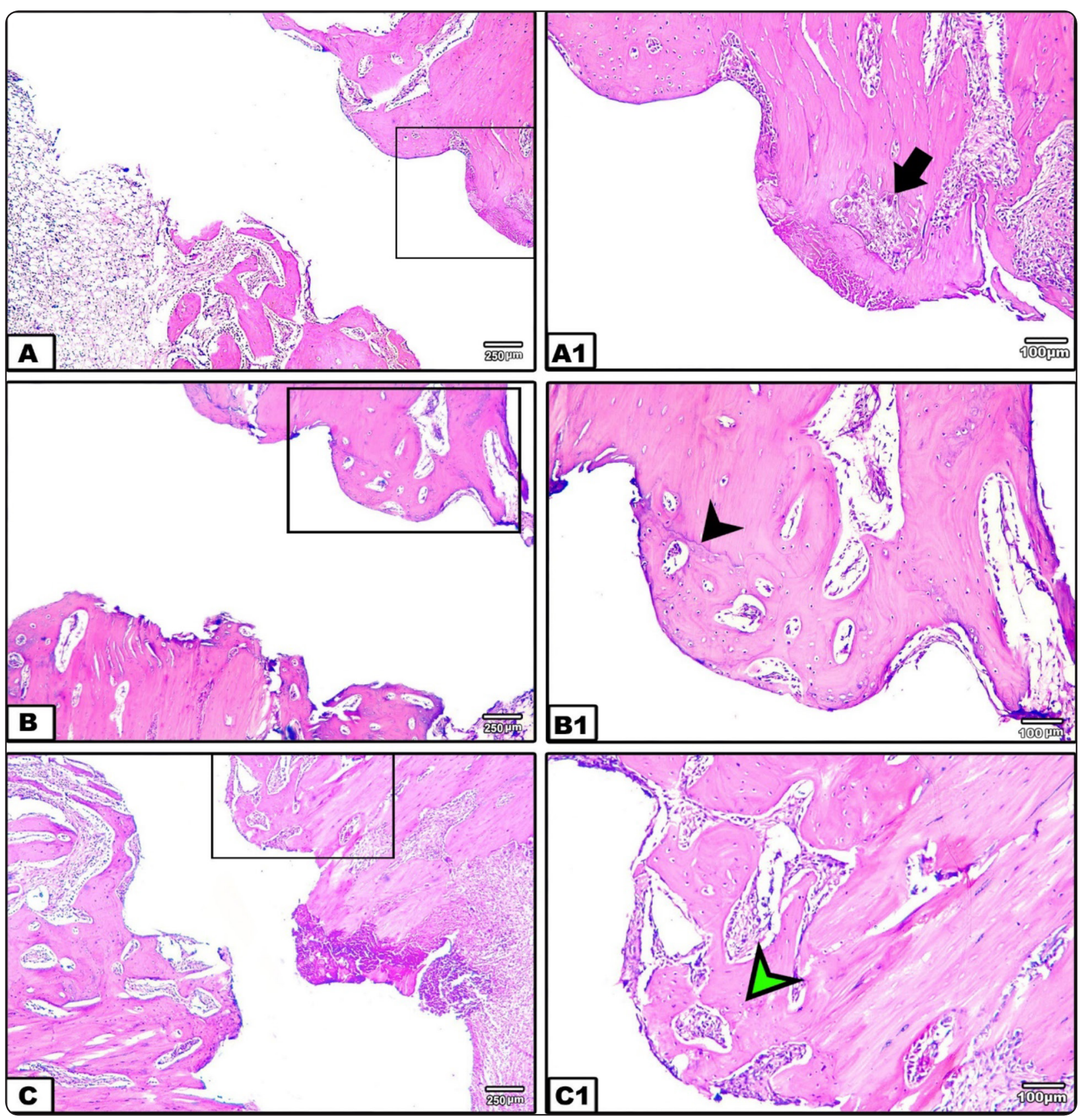

Fig. (3). Histological images showing osseointegration after 4weeks. (A, A1) showing few new bone formation of group I with increase bone marrow spaces (arrow). (B, B1) showing more formation of new bone trabeculea in group II with line of demarcation between old and new bone (arrow head). (C, C1) showing disorganized new bone formation in group III (green arrow head). (A, B, C original magnification 40x) (A1, B1, C1 original magnification 100x). 


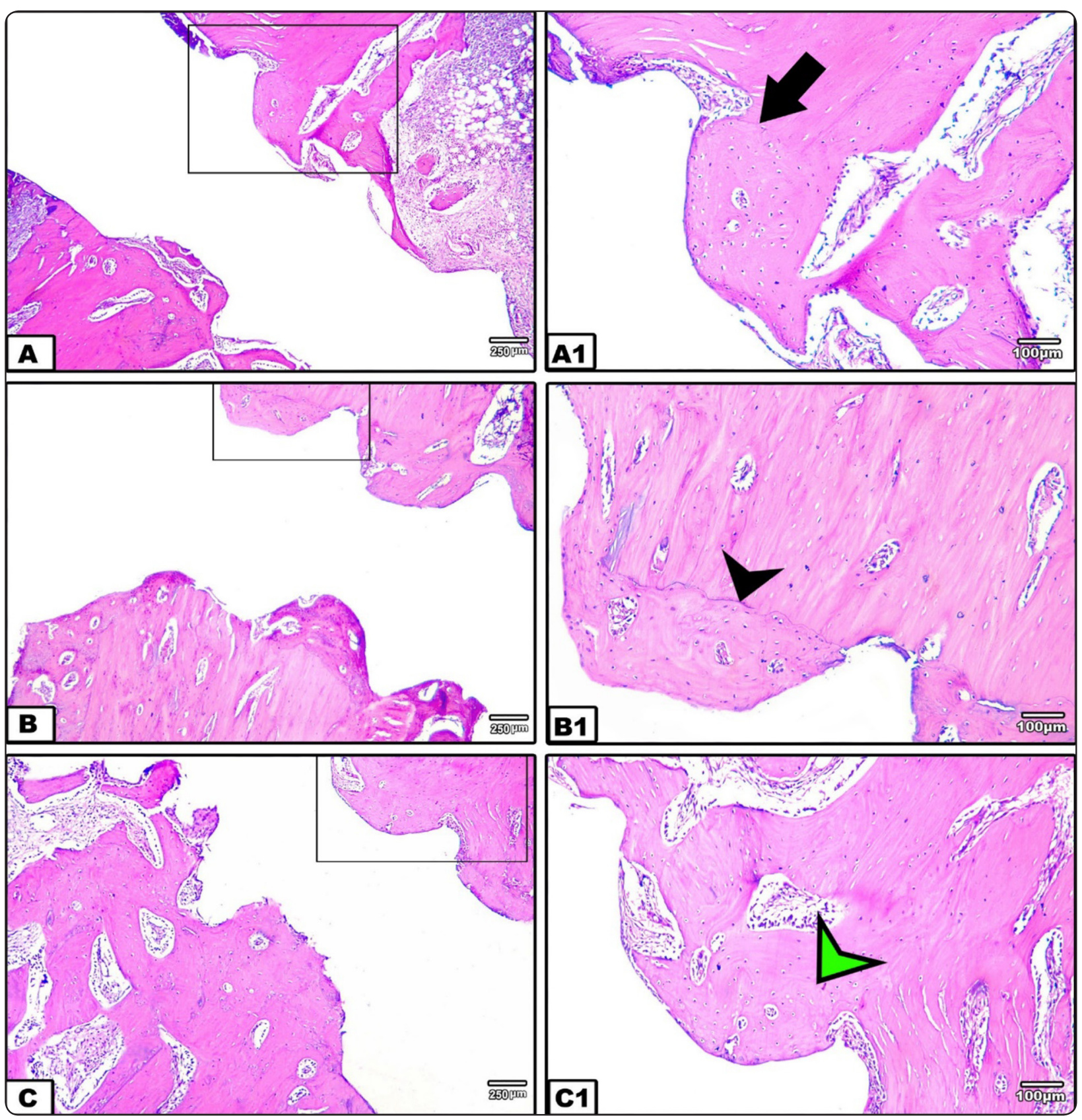

Fig. (4). Histological images showing osseointegration after 8weeks. (A, A1) showing increased bone formation in group I (arrow). $(\mathrm{B}, \mathrm{B} 1)$ showing more thickened new bone trabeculea with line of demarcation between old and new bone in group II (arrow head). (C, C1) showing more organized bone trabeculea in group III (green arrow head). (A, B, C original magnification 40x) (A1, B1, C1 original magnification 100x). 

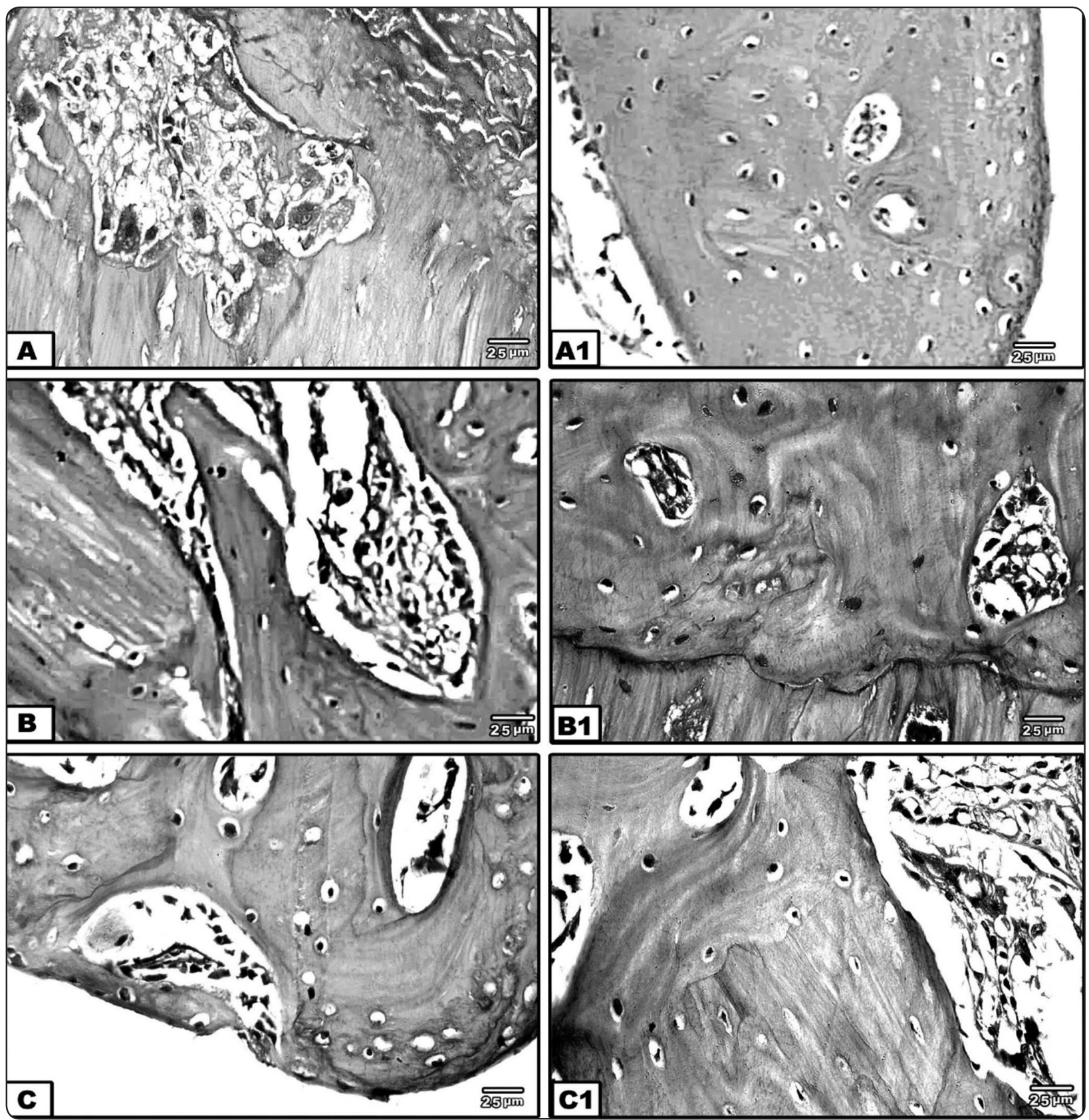

Fig. (5). Photomicrograhic pictures of bone- implant interface with alkaline phosphatase enzyme. (A) Group I after 4 weeks with mild reaction. (B) Group II after 4 weeks also with mild reaction. (C) Group III after 4 weeks also with mild reaction. (A1) Group I after 8 weeks with intense reaction. (B1) Group II after 8 weeks with highly intense reaction. (C1) Group III after 8 weeks with moderate reaction. (Alkaline phosphatase X 400) (Scale bar=25) 


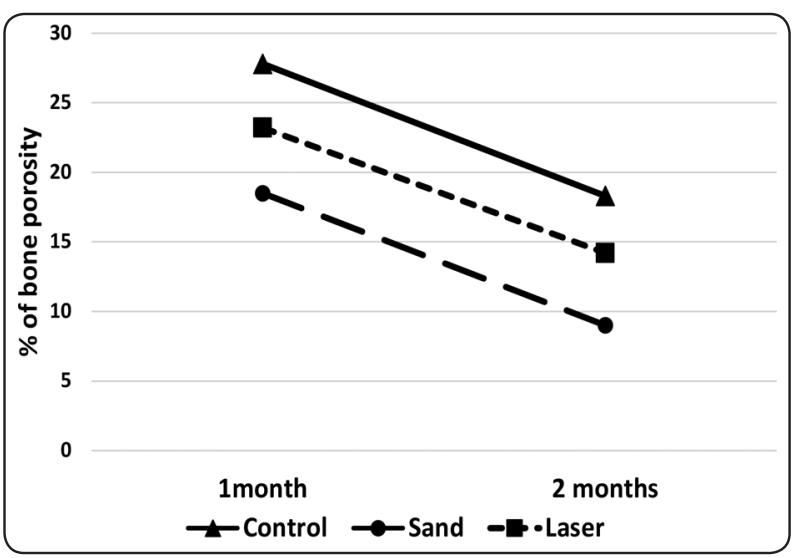

Fig. (6). Area fraction of bone porosity in all studied groups across follow up points.

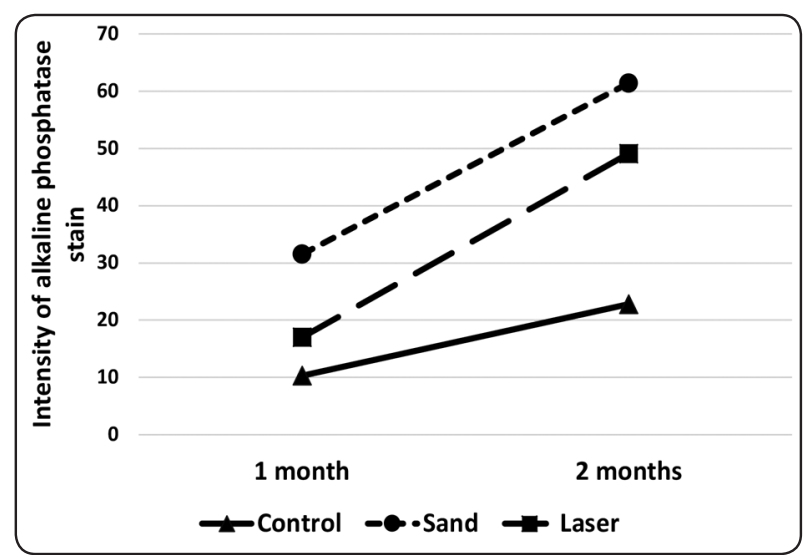

Fig. (7). Area fraction of alkaline phosphatase stain in all studied groups across follow up points.

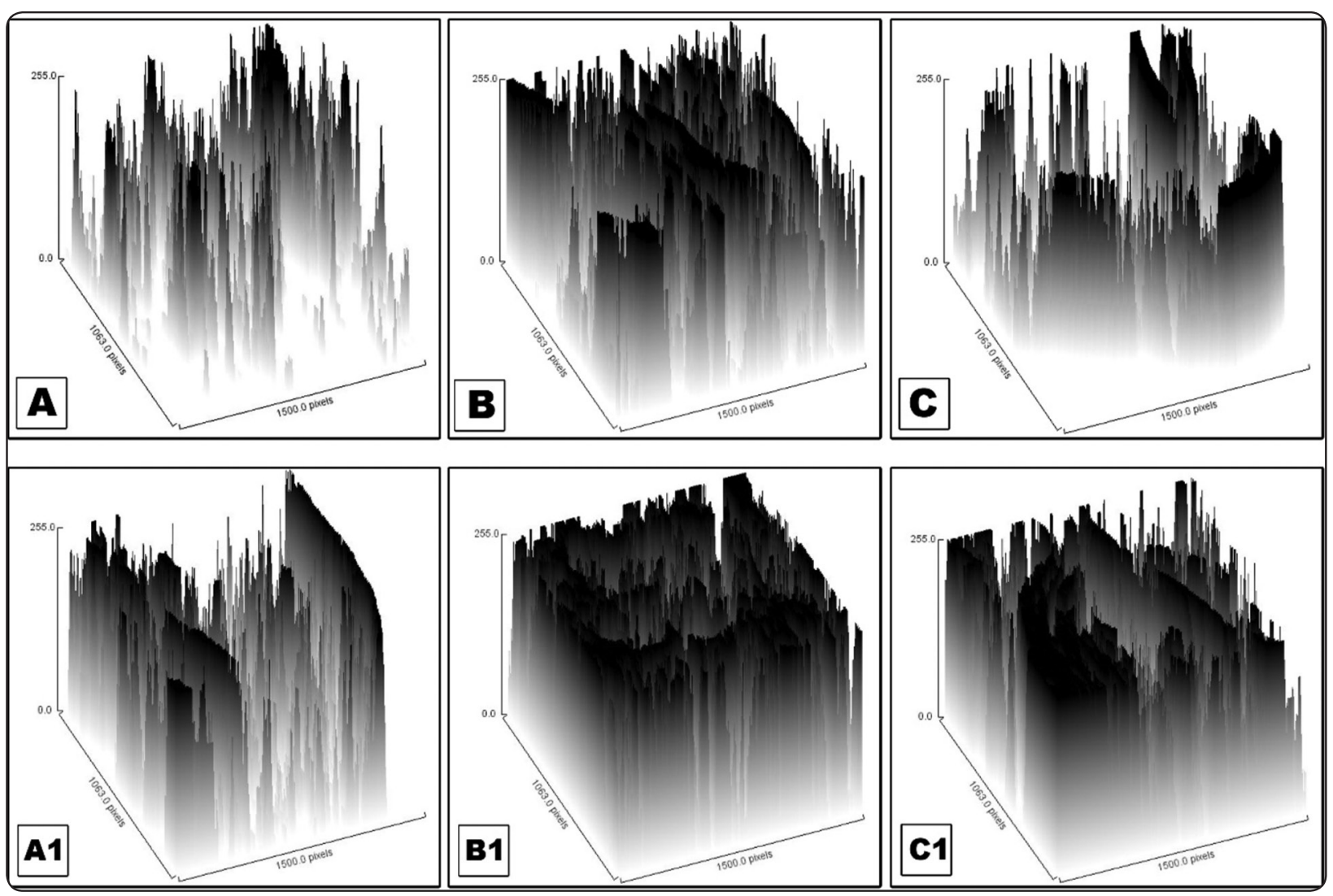

Fig. (8). Surface plot of mean pixel intensity of alkaline phosphatase stain. (A) Group I after 4 weeks. (B) Group II after 4 weeks. (C) Group III after 4 weeks. (A1) Group I after 8 weeks. (B1) Group II after 8 weeks. (C1) Group III after 8 weeks. 


\section{DISCUSSION}

Implant-supported skeletal anchorage for orthodontics is an exciting and novel clinical field. Its applications are ongoing to expand and become a crucial component of the recent research. Although these special orthodontic mini- screw anchorages have been extensively researched in the literature for more than 15 years ${ }^{33,34}$, the risk of root contact and the latent instability that lead to critical longterm success are reported ${ }^{5,8}$. Thus, continuing researches that demands more rigorous control of the technical variables involved and modifications of surface properties became necessary to improve the patient care. The current study was carried out to investigate the effect of 2 different types of surface modifications on implant topography and osseointegration to the treated titanium orthodontics mini-implants.

High standard of osseointegration is critical to assure good stability of dental implants. Surface properties of a dental implant may have an essential role in osteoblast adsorption, adhesion and proliferation on its surface, and thus affect the implant osseointegration. However, the selection of the most favorable surface characteristics is still not well-defined and hence it is still under investigation 31,35. Therefore, the current study tested the influence of sandblasting and $\mathrm{Nd}$ :YAG laser treatment on the surface topography of titanium mini-screws. Scanning electron micrographs and $\mathrm{Ra}$ results revealed a significant roughening effect of both methods on the surface of titanium implants, with more pronounced values of the sandblasted screws. The roughening effect of sandblasting on the surface of titanium was investigated by Velasco-Ortega et. al. ${ }^{36}$ in a recent study. The authors of that study compared the effects of sandblasting to that of acid etching and oxidization of titanium implants. They attributed the prompt roughness of the sandblasted surface to the effect of the abrasive particles which roughen the surface depending on their hardness, size, and nature, and also on the applied pressure during sandblasting. They concluded that the impingement produced by the sand particles, combined with pressure of the blasting gun, yields areas of residual stresses and plastic strain on the implant surface, which enhances adhesion of osteoblasts and improves osseointegration of the implant ${ }^{37,38}$. Another study by Helal et. al. (2010) ${ }^{31}$ investigated the effect of laser treatment on titanium surface and they stated that higher power Nd:YAG laser elevated the surface roughness of implant, which improved osseointegration, depending on the absorptive potential of titanium towards this kind of laser.

Rabbits' femur and tibiae have been widely used for samples implantation by various authors as this methodseems to be a convenient model for investigation of bone healing process ${ }^{\mathbf{2 0 , 3 9 - 4 2}}$. The healing periods investigated by different studies to assess the bone-implant bond in rabbits ranged from 2-12 weeks ${ }^{43-45}$. In concurrent to these previous studies, our research used the rabbit tibia as an appropriate implant sites for the mini-implants, with 4and 8 weeks healing periods that were carefully chosen after thorough review of the literature $\mathbf{4 3 , 4 6 , 4 7}^{\mathbf{4}}$.

In the current study, histological, histochemical and histomorphometric analyses were used. Bernhardt et al. (2012) ${ }^{48}$ and Maglio et al. (2020) ${ }^{49}$ reported histological imaging as the gold standard for analyzing bone formation around metallic implants, as this method allows for the detection of inflammatory and cellular changes that cannot be detected by radiographic examination alone.

In the present study, it was observed that lamellar bone was apparently formed in group II (sandblasted) and group III (laser-treated), but the results were more significant among group II after 4 and 8 weeks. These results were in agreement with Velasco-Ortega et al. (2019) ${ }^{36}$ who reported higher macro and micro-roughness of the sandblasted and acid-etched implants with elevated bone index contact in comparison to the oxidized implant surfaces. They also found that bone formation and anchorage were slightly higher with the sandblasted 
and etched implants, and this was attributed to the elevated roughness and residual stresses.

By calculation of \% area of bone porosity around implant in relation to total bone area, the current research revealed a significant difference between all studied groups after 4weeks $(\mathrm{p} 1<0.001)$. In addition, laser-treated group showed significantly lower mean when compared to sand-blasted group $(\mathrm{p} 4<0.001)$. This is in accordance with Goymen et al. (2015) $)^{50}$ who concluded that laser treatment results in better bone to implant contact, which indicates a higher stability.

Alkaline phosphatase is a membrane-bound glycoprotein enzyme and its function is to catalyze the hydrolysis of phosphate monoesters ${ }^{51}$. In this study with regarding alkaline Phosphatase enzyme reaction, group II was significantly having intense reaction that reveals an increased activity of the enzyme in bone formation. This came is an agreement with Chang et al. (2016) ${ }^{52}$ who reported that alkaline phosphatase levels represent the osteoblast activity and bone formation rate, because this enzyme is obtained from osteoblasts during osteogenic differentiation.

\section{CONCLUSION AND RECOMMENDATION}

Based on surface evaluation, quantitative and qualitative measures of osseointegration, it could be concluded that sandblasted titanium mini-screws exhibited a superior bone to implant bond than that of the laser-treated ones. However, further investigation is recommended to evaluate the amount of bone destruction on removal of the screw at the end of the orthodontic treatment course.

\section{REFERENCES}

1. Buchter A, Wiechmann D, Koerdt S, Wiesmann HP, Piffko J, Meyer U. Load related implant reaction of mini-implants used for orthodontic anchorage. Clin Oral Implants Res 2005;16: 473-479.

2. Mazor Z, Steigmann M,Leshem R, Peleg M. Mini-implants to reconstruct missing teeth in severe ridge deficiency and small interdental space: a 5- year case series. Implant Dent 2004;13: 336-341.

3. Yeh S, Monaco EA, Buhite RJ. Using transitional implants as fixation screws to stabilize a surgical template for accurate implant placement: a clinical report. J Prosthet Dent 2005;93: 509-413.

4. Kwon KR, Sachdeo A, Weber HP. Achieving immediate function with provisional prostheses after implant placement: a clinical report. J Prosthet Dent 2005;93: 514-517.

5. Kuroda S, Sugawara Y, Deguchi T, Kyung HM, Takano- Yamamoto T. Clinical use of mini-implant implants as orthodontic anchorage: Success rates and postoperative discomfort. Am J Orthod Dentofacial Orthop 2007; 131: 9-15.

6. BranemarkP, Adell R,BreineU, HanssonB, LindströmJ, Ohlsson A. Intra-osseous anchorage of dental prostheses. I. Experimental studies. Scand J Plast Reconstr Surg 1969;3: 81-100.

7. Anil S, Alghamdi H, Jansen J, Anand P. Dental implant surface enhancement and osseointegration. In: Turkyilmaz I (ed) Implant dentistry - a rapidly evolving practice. InTech, Croatia, 2011; 83-108.

8. Vilani GN, Ruellas AC, Elias CN3, Mattos CT. Stability of smooth and rough mini-implants: clinical and biomechanical evaluation - an in vivostudy. Dental Press J Orthod 2015;2: 35-42.

9. Albrektsson T, Branemark PI, Hansson HA, Lindstrom J. Osseointegrated titanium implants. Requirements for ensuring a long-lasting, direct bone-to-implant anchorage in man. Acta Orthop Scand 1981;52:155-170.

10. Le Guehennec L, Soueidan A, Layrolle P, Amouriq Y. Surface treatments of titanium dental implants for rapid osseointegration. Dent Mater 2007;23: 844-854.

11. Zreiqat H, Valenzuela SM, Nissan BB, Roest R, Knabe C, Radlanski RJ, Renz H, Evans PJ. The effect of surface chemistry modification of titanium alloy on signalling pathways in human osteoblasts. Biomaterials 2005; 26(36):7579-7586.

12. Gittens RA, Scheideler L, Rupp F, Hyzy SL, Geis-Gerstorfer J, SchwartzZ, BoyanBD.A review on the wettability of dental implant surfaces II: biological and clinical aspects. Acta Biomater 2014;10: 2907-2918.

13. Menezes HHM, Naves MM, Costa HL, Barbosa TP, Ferreira JA, Magalhães D, Martinez EF. Effect of surgical installation of dental implants on Surface topography and its influence on osteoblast Proliferation. Int J Dent 2018;17:1-13. 
14. de Avila ED, de Molon RS, Lima BP, Lux R, Shi W, Junior MJ, SpolidorioDM, VerganiCE, deAssis MolloJunior F. Impact of physical chemical characteristics of abutment implant surfaces on bacteria adhesion. J Oral Implantol 2016; 42:153-158.

15. O'Hare P1, Meenan BJ, Burke GA, Byrne G, Dowling D, Hunt JA. Biological responses to hydroxyapatite surfacs deposited via a coincident microblasting technique. Biomaterials 2010;31:515-522.

16. Cho IS1, Kim SK, Chang YI, Baek SH. In vitro and in vivo mechanical stability of orthodontic mini-implants: Effect of sandblasted, large-grit, and anodic-oxidation vs sandblasted, large-grit, and acid-etching. Angle Orthod 2012;82: 611-617.

17. Gehrke SA, Ramírez-Fernandez MP, Granero Marín JM, Barbosa Salles M, Del Fabbro M, Calvo Guirado JL. A comparative evaluation between aluminium and titanium dioxide microparticles for blasting the surface titanium dental implants: an experimental study in rabbits. Clin Oral Implants Res 2018; 29:802-807.

18. Gaggl A, Schultes G, Muller WD, Karcher H. Scanning electron microscopical analysis of laser-treated titanium implant surfaces-a comparative study. Biomaterials 2000; 21:1067-1073.

19. Pető G, Karacs A, Pászti Z, Guczi L, Divinyi T, Joób A. Surface treatment of screw shaped titanium dental implants by high intensity laser pulses. Appl Surf Sci 2002; 186:7-13.

20. Faeda RS1, Tavares HS, Sartori R, Guastaldi AC, Marcantonio E Jr. Evaluation of titanium implants with surface modification by laser beam. Biomechanical study in rabbit tibias. Braz Oral Res 2009;23(2):137-143.

21. Deppe H, Horch HH. Laser applications in oral surgery and implant dentistry. Lasers Med Sci2007; 22:217-221.

22. Park CY, Kim SG, Kim MD, Eom TG. Yoon JH, Abn SG Surface properties of endosseous dental implants after NdYAG and Co2 laser treatment at various energies. J Oral Maxillofacial Surg 2005; 63:1522-1527.

23. Mortensen MG, Buschang PH, Oliver DR, Kyung HM, Behrents RG. Stability of immediately loaded 3- and 6-mm miniscrew implants in beagle dogs--a pilot study. Am J Orthod Dentofacial Orthop 2009; 136: 251-259.

24. Kang SH, Cho SA. Comparison of removal torques for laser treated titanium implants with anodized implants. J Craniofac Surg 2011; 22: 1491-1495.
25. Kannatey-Asibu E. Principles of lase materials processing. Wiley Series on Processing of Engineering Materials 2009; 4:507.

26.Hindy A, Farahmand F, Tabatabaei FS. In vitro biological outcome of laser application for modification or processing of titanium dental implants. Lasers Med Sci 2017; 32:1197-1206

27. Shi GS, Ren LF, Wang LZ, Lin HS, Wang SB, Tong YQ. $\mathrm{H} 2 \mathrm{O} 2 / \mathrm{HCl}$ and heat-treated Ti-6Al-4V stimulates preosteoblast proliferation and differentiation. Oral Surgery, Oral Medicine, Oral Pathology, Oral Radiology, and Endodontics2009; 108(3):368-375.

28. Chrcanovic BR, Leão NLC, Martins MD. Influence of different acid etchings on the superficial characteristics of Ti sandblasted with Al2O3. Materials Research 2013; 16:1006-1014

29. Ledingham AD, Şar Ç, English JD, Akyalçın S. Is there a difference between the primary stability of anodized and non-anodized mini-screws subjected to repeated cycles of autoclave sterilization? Cumhuriyet Dental Journal 2014; $17: 129-134$.

30. Yang GL, He FM, Yang XF, Wang XX, Zhao SF. Bone responses to titanium implants surface-roughened by sandblasted and double etched treatments in a rabbit model. Oral Surgery, Oral Medicine, Oral Pathology and Oral Radiology 2008;106:516-24.

31. Helal M, Zaghlool M,Gad E.: Effect of different titanium laser surface treatments on ossointegration. INT J Acad Res2010;2:18-144.

32. Slaets E, Carmeliet G, Naert I, Duyck J. Early cellular responses in cortical bone healing around unloaded titanium implants: an animal study. J Periodontol 2006; 77:1015-1024

33. Costa A, Raffainl M, Melsen B: Miniscrews as orthodontic anchorage: preliminary report. Int $\mathrm{J}$ Adult Orthodon Orthognath Surg 1998; 13:201-209.

34. Fritz U, Ehmer A, Diedrich P: Clinical suitability of titanium miniscrews for orthodontic anchorage-preliminary experiences. J Orofac Orthop 2004;65:410-418.

35. Eliasa, CN, Rocha, FA, Nascimento, AL, Coelho PG. Influence of implant shape, surface morphology, surgical technique and bone quality on the primary stability of dental implants. J Mech Behav Biomed Mater 2012; 16:169-80. 
36. Velasco-Ortega E, Ortiz-García I, Jiménez-Guerra A, Monsalve-Guil L, Muñoz-Guzón F, Perez RA, Gil FJ. Comparison between Sandblasted Acid-Etched and Oxidized Titanium Dental Implants: In Vivo Study. Int J Mol Sci 2019; 3;20:3267-77.

37. Gil FJ, Planell JA, Padros A, Aparico C. The effect of shot blasting and heat treatment on the fatigue behavior of titanium for dental implant applications. Dent Mater 2007; 23, 486-91.

38. Aparicio C, Padros A, Gil FJ. In vivo evaluation of microrough and bioactive titanium dental implants using histometry and pull-out tests. J Mech Behav Biomed Mater 2011; 4, 1672-82

39. An YH, Woolf SK, Friedman RJ. Pre-clinical in vivo evaluation of orthopaedic bioabsorbable devices. Biomaterials 2000;21:2635-52.

40. Rong M, Zhou L, Gou Z, Zhu A, Zhou D. The early osseointegration of the laser-treated and acid-etched dental implants surface: an experimental study in rabbits. J Mater Sci Mater Med 2009; 20:1721-8.

41. Marin C, Bonfante EA, Granato R, Suzuki M, Granjeiro JM, Coelho PG. The effect of alterations on resorbable blasting media processed implant surfaces on early bone healing: a study in rabbits. Implant Dent 2011; 20:167-77.

42. Yildiz A, Esen E, Kurkcu M, Damlar I, Daglioglu K, Akova T. Effect of zoledronic acid on osseointegration of titanium implants: an experimental study in an ovariectomized rabbit model. J Oral Maxillofac Surg 2010; 68:515-23.

43. Sul YT, Byon ES, Jeong Y. Biomechanical measurements of calciumincorporated oxidized implants in rabbit bone: effect of calcium surface chemistry of a novel implant. Clin Implant Dent Relat Res 2004; 6:101-10.
44. Svanborg LM, Hoffman M, Andersson M, Currie F, Kjellin $\mathrm{P}$, Wennerberg A. The effect of hydroxyapatite nanocrystals on early bone formation surrounding dental implants. Int $\mathbf{J}$ Oral Maxillofac Surg 2011; 40:308-15.

45. Breding K, Jimbo R, Hayashi M, Xue Y, Mustafa K, Andersson M. The effect of hydroxyapatite nanocrystals on osseointegration of titanium implants: an in vivo rabbit study. Int J Dentistry 2014; 2014:171305.

46. Ahn MR, An KM, Choi JH, Sohn DS. Immediate loading with mini dental implants in the fully edentulous mandible. Implant Dent 2004;13(4):367-72.

47. Klokkevold PR, Johnson P, Dadgostari S, Caputo A, Davies JE, Nishimura RD. Early endosseous integration enhanced by dual acid etching of titanium: a torque removal study in the rabbit. Clin Oral Implants Res 2001;12(4):350-7.

48. Bernhardt R, Kuhlisch E, Schulz M C, Eckelt U, Stadlinger B. Comparison of bone-implant contact and bone-implant volume between 2D-histological sections and 3D-SR $\mu \mathrm{CT}$ slices. Eur Cell Mater 2012;10(23):237-47.

49. Maglio M, Salamanna F, Brogini S, Borsari V, Pagani S, Nicoli Aldini N, Giavaresi G, Fini M . Histological, Histomorphometrical, and Biomechanical Studies of Bone-Implanted Medical Devices: Hard Resin Embedding. Biomed Res Int 2020,17; 2020:1804630.

50. Goymen M, Isman E, Taner L, Kurkcu M. Histomorphometric Evaluation of the Effects of Various Diode Lasers and Force Levels on Orthodontic Mini Screw Stability. Photomed Laser Surg 2015, 1; 33(1): 29-34.

51. Sharma U, Pal D, Prasad R. Alkaline phosphatase: an overview. Indian J Clin Biochem 2014; 29:269-278.

52. Chang B, Song W, Han T, et al. Influence of pore size of porous titanium fabricated by vacuum diffusion bonding of titanium meshes on cell penetration and bone ingrowth. Acta Biomater 2016; 33:311-321. 